\title{
Correspondência entre as Patentes da UFRGS ea Classificação Nacional das Atividades Econômicas ${ }^{1}$
}

\author{
Autor: \\ Gisele Spricigo (UNISINOS)
}

\section{Coautores: \\ Aziz Calzolaio (UFRGS); Sérgio M. M. Monteiro (UFRGS)}

\begin{abstract}
Resumo: A interação universidade-empresa constitui-se como importante elemento para o desenvolvimento econômico das nações. Embora ainda tímidas as estatísticas de patentes enquanto fruto desta interação no Brasil, este artigo indica um caminho, a fim de realizar um exercício de correspondência entre as patentes da UFRGS e as atividades econômicas, o que contribuirá para visualizar os setores produtivos que possuem maior potencial para absorver as tecnologias criadas nesta universidade. Para realizar tal correspondência utilizou-se a metodologia proposta por Lybbert e Zolas (2014). Utilizou-se duas ferramentas estatísticas: a análise de correspondência e o teste Qui Quadrado $\left(x^{2}\right)$. Conclui-se que $76 \%$ das patentes da UFRGS estariam conjugadas a somente 6 das 87 Divisões da Classificação Nacional das Atividades Econômicas (CNAE) e que o maior número de patentes da UFRGS está no campo científico da química medicinal. Sendo assim, esta universidade parece ter um grande potencial para interagir com a indústria de medicamentos, defensivos agrícolas e vacinas veterinárias. Além disso, verificou-se uma forte produção de conhecimento voltado a tecnologias de instrumentos que investigam propriedades de diferentes materiais.
\end{abstract}

Palavras-chave: Patentes; Atividades Econômicas; Transferência Tecnológica; Universidades. Classificação Jel: O31; O32; 034; O38.

Abstract: Industry-university interactions is a key element for the economic development. Despite this, the knowledge about how those actors interact still needs to improve. This article going on to construct a concordance between the UFRGS'patents and economic activities in order to improve methodologies which gives support to the technology transfer from university to industries. To do this work, it used an approach came from Lybbert and Zolas (2014) in order to perform the association between UFRGS 'patents and economic activities. Furthermore, it was used two statistical tools to support that match: the Correspondence Analysis and the Chi-square test $\left(x^{2}\right)$. The main findings were both $76 \%$ of the UFRGS patents would be combined with only 6 of the 87 Divisions of Brazilian Classification of Economic Activities (CNAE) and the major number of UFRGS patents finds lock in chemistry scientific field which is linked to the medicines. So, UFRGS may has big potential to interact with medicines industries which produces veterinary vaccines, human medicines and pesticides. Finalily, UFRGS academic research also highlight big capacity in the production of instrument technologies for investigations of the properties of different materials.

Keywords: Patents; Economic activities; Technology Transfer; Universities.

JEL Classification:O31; O32; 034; O38

\section{INTRODUÇÃO}

A interação universidade-empresa (IUE) constitui-se como importante elemento para o desenvolvimento econômico das nações. Ainda mais em um momento em que a ciência e a Pesquisa e Desenvolvimento (P\&D) constituem-se como insumos para produção de produtos e serviços. Com isso, as atividades atribuídas ao capital intangível têm aumentado sua participação relativa no Produto Interno Bruto

\footnotetext{
${ }^{1}$ Esse trabalho é parte dos resultados da Bolsa de Pós-Doutorado - DOCFIX - Edital CAPES-FAPERGS n ${ }^{\circ}$ 05-2013, da qual Aziz Eduardo Calzolaio foi bolsista de set. de 2015 a out. de 2016. Agradecemos o apoio financeiro da FAPERGS E CAPES.
} 
(PIB). Porém, pouco se sabe a respeito dos mecanismos subjacentes à transferência tecnológica (BUENSTORF; GEISSLER, 2012).

O conhecimento científico, enquanto fruto da IUE, torna-se um fator decisivo para o desenvolvimento da inovação industrial. Isso tem conduzido ao aumento da comercialização dos resultados das pesquisas acadêmicas (MUELLER e PERUCCHI, 2014). A Lei de $\mathrm{n}^{\circ} 10.973$ de 2004, chamada de Lei da Inovação, introduziu uma grande mudança institucional para as Instituições de Ciência e Tecnologia $(\mathrm{ICT})^{2}$ brasileiras, como a permissão, aos grupos de pesquisas de diversas organizações acadêmicas comercializassem os resultados das suas pesquisas tecnológicas. Desde então, o incentivo à transferência tecnológica das ICT para as demais organizações da sociedade é alvo constante de aprimoramento.

A política de inovação, adotada desde 2004, também regulamentou os Núcleos de Inovação Tecnológica (NIT) das instituições de ensino superior. Eles incentivam e promovem tanto a proteção intelectual, como a comercialização das tecnologias de maneira eficiente (CASTRO; SOUZA, 2012). Ademais, a importância das descobertas científicas para a inovação das empresas conduziu os gestores de patentes $^{3}$ a visualizarem estas como ativos com potencial econômico.

Este artigo propõe estabelecer uma relação das patentes da Universidade Federal do Rio Grande do Sul (UFRGS) com as atividades econômicas (setores econômicos) que potencialmente seriam receptoras. Entendo essa relação, tem-se um diagnóstico que pode contribuir para o aperfeiçoamento de metodologias e processos que buscam estabelecer critérios para a transferência de tecnologias criadas nas universidades. Nesse sentido, o principal objetivo desse artigo é realizar a correspondência entre os códigos da International Pantent Classification (IPC), utilizados nas patentes da UFRGS, com as atividades econômicas da Classificação Nacional das Atividades Econômicas (CNAE). Isso contribuirá para o entendimento de quais atividades produtivas são potenciais receptoras das tecnologias protegidas por essa universidade. Com isso, ainda, pode-se tentar visualizar futuras utilidades práticas das criações advindas das pesquisas, vinculando às possíveis atividades econômicas que teriam interesse em receptar tais criações. Assim, justifica-se a importância de se reconhecer a conexão das tecnologias patenteadas às atividades econômicas.

Essa abordagem é explanatória, visto que é o primeiro estudo deste tipo no Brasil. Ele é baseado na proposta de Lybbert e Zolas (2014) e para desenvolvê-lo foi aplicado duas ferramentas estatísticas: a análise de correspondência, e o teste Qui Quadrado $x^{2}$.

Além desta introdução, este artigo tem mais quatro partes. A seção 2 explora a relação universidadeempresa, sua importância e discute o processo de patenteamento nas universidades. A seção 3 discute a correspondência entre classificações tecnológicas e econômicas. A seção 4 apresenta a metodologia utilizada, bem como as ferramentas estatísticas aplicadas, para realizar a associação entre a IPC das patentes da UFRGS e a CNAE. Já a seção 5 apresenta e discute os resultados da referida associação e, por fim, a seção 6 contém as considerações finais.

\section{TRANSFERÊNCIA TECNOLÓGICA E PATENTES}

As universidades fornecem conhecimentos imprescindíveis para a moderna produção industrial e isso gera impacto no crescimento econômico (POWELL; SNELLMAN, 2004). Isso é evidenciado através do crescimento do número de licenciamentos cujo objetivo é transferir a propriedade intelectual das universidades para as empresas (THURSBY et al2007). Ou seja, tem havido um crescimento da comercialização dos resultados das pesquisas acadêmicas em vários países (MUELLER e PERUCCHI, 2014). Para que isso fosse operacionalizado, as invenções acadêmicas começaram a ser protegidas de forma mais intensa (PEREIRA; MELO, 2015), criando um ativo para posterior negociação com empresas.

\footnotetext{
${ }^{2}$ Instituição Científica, Tecnológica e de Inovação (ICT) é definido pela Lei no $13.243 / 2016$ como órgão ou entidade da administração pública direta ou indireta ou pessoa jurídica de direito privado sem fins lucrativos que inclua em sua missão a pesquisa básica ou aplicada de caráter científico ou tecnológico ou o desenvolvimento de novos produtos, serviços ou processos (BRASIL, 2016).

${ }^{3}$ Patentes são definidas como títulos de propriedade temporária sobre uma invenção ou modelo de utilidade que atenda ao requisito de novidade. Elas concedem aos seus detentores um direito exclusivo, sob a tutela do Estado, de explorá-las. (INPI, 2016b).
} 
As universidades passaram a proteger suas criações de maneira sistematizada, criando estruturas de gestão de certificados de propriedade intelectual, como a patente, por exemplo. Com isso, o resultado da investigação acadêmica passa a ser de posse exclusiva da instituição que as originou, passível, assim, de serem exploradas economicamente. Em outras palavras, as inovações devidamente registradas são ativos intangíveis que possuem potencial valor comercial (MUELLER; PERUCCHI, 2014) cuja remuneração chama-se royalities ${ }^{4}$.

A participação das ICT em pesquisas voltadas ao interesse econômico privado suscitou o debate acerca do desvio das funções básicas das instituições de ensino, as quais estariam comprometendo o desenvolvimento da ciência básica em favor da aplicação, com o intuito de solucionar problemas das empresas (BOYD et al, 2003). Em contrapartida, alguns autores defendem que é possível a pesquisa voltarse ao empreendimento econômico e, ainda assim, manter seu objetivo acadêmico e científico fundamental, preservando o papel basilar da universidade (THURSBY et al 2007).

A Bayh-Dole Act, instituída em 1980, foi o marco fundamental que potencializou a comercialização das tecnologias criadas nas ICT ao encorajar os pesquisadores, mesmo os de instituições públicas, a patentearem suas invenções afim de comercializá-las (PÓVOA, 2008). Da mesma forma, outros países da OCDE e da Europa criaram suas respectivas leis de inovação. Desde de então, aprofundou-se um uso não convencional das patentes universitárias, o chamado licenciamento que possibilita retorno financeiro (OECD, 2009).

No Brasil, já na década de 2000, despertou para esse movimento de proteção do conhecimento produzido nas universidades, visando sua posterior comercialização. Isso ocorreu de forma acelerada após a Lei da Inovação (Lei n ${ }^{\circ} 10.973 / 04$ ). Desde então, houve um crescimento exponencial da busca por registro de propriedade intelectual nas universidades brasileiras, que até meados da década de 2000 era extremamente baixo (OLIVEIRA; NUNES, 2009). A Lei da Inovação lançou os fundamentos da nova política de inovação brasileira ao introduzir consideráveis mudanças institucionais, dentre elas a permissão da comercialização dos resultados da investigação dos grupos de pesquisas. Até mesmo as tecnologias criadas dentro das ICT públicas com financiamento governamental podem ser vendidas.

A partir do novo arcabouço legislativo (Lei $\mathrm{n}^{\circ}$ 10.973/04) foram criados os NIT, estruturas que realizarem a gestão da política institucional de inovação das ICT. Eles estimulam e formalizam as proteções das criações desenvolvidas naquelas instituições, bem como mediam as ações de transferência tecnológica. A Lei da Inovação de 2004 foi aperfeiçoada através da Lei 13.243 de 2016, a qual buscou intensificar o licenciamento, a transferência tecnológica e o uso ou exploração de tecnologias universitárias.

Em resumo, as universidades possuem um papel central no desenvolvimento de inovações e patentes que podem contribuir com o desenvolvimento econômico (THURSBY et al 2007). Por isso surgiram políticas que encorajaram as ICT à protegerem suas invenções com o objetivo de comercializá-las (PÓVOA, 2008). Com todas essas medidas, o número de patentes cresceu consideravelmente.

Não foi diferente com relação à UFRGS, como exposto pelo gráfico 1. Após a Lei da Inovação, 2004, o número de pedidos de patentes anuais cresceu de 12, em 2004, para, 49, em 2012. Mesmo com o decrescimento a partir de 2013, as solicitações mantêm-se bem acima das que foram realizadas antes de 2004. O crescimento médio anual no número de solicitação de patentes, de 2004 até 2014, foi de 11,6\%.

\section{Gráfico 1 - Número de solicitação anual de patentes da UFRGS}

\footnotetext{
${ }^{4}$ Além disso, a negociação das criações científicas da academia ocorre por outros canais, como o licenciamento de tecnologia, a prestação de serviços tecnológicos, a criação de spin-off, o P\&D colaborativo, a incubação de empresas e a instalação de empresas nas universidades por intermédio dos parques tecnológicos (WORLD BANK; OECD, 2013).
} 


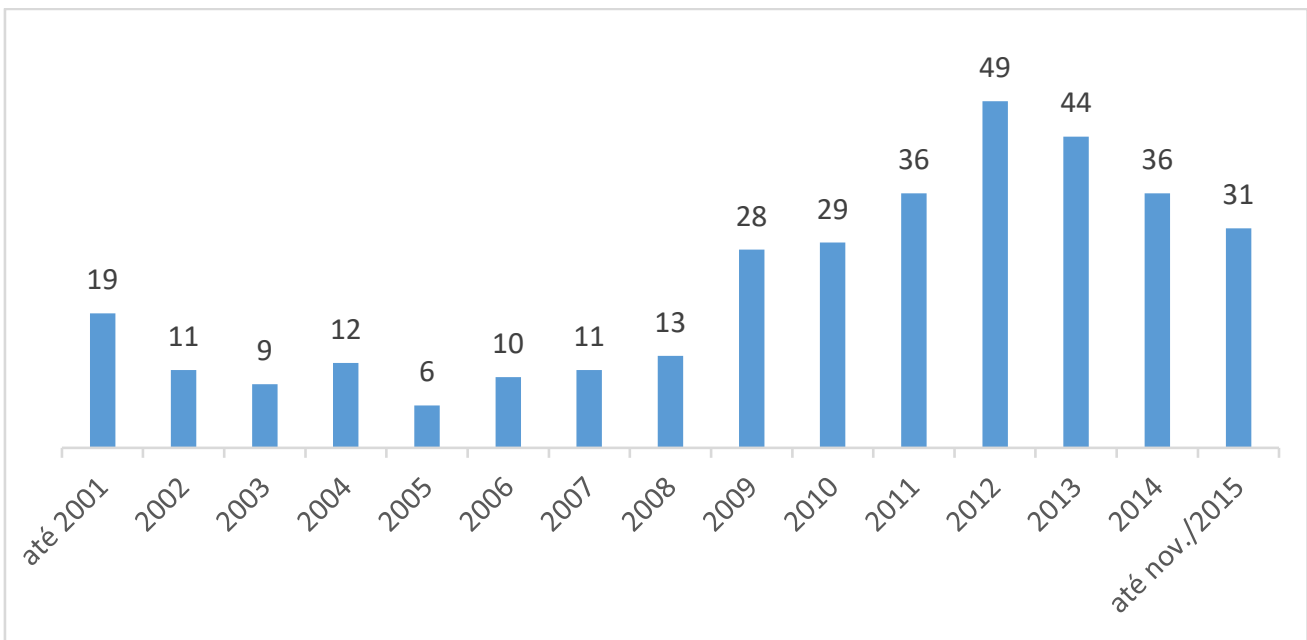

Fonte: elaboração própria a partir dos dados da SEDETEC/UFRGS.

A importância das descobertas científicas para a inovação das empresas levou as universidades a considerar possíveis aplicações econômicas das invenções protegidas. Uma forma de se tentar visualizar futuras utilidades práticas das criações advindas das pesquisas é vinculá-las às possíveis atividades econômicas que teriam interesse em receptar tais criações. Por isso, a seguir, é debatido proposta de conexão das tecnologias patenteadas às atividades econômicas.

\subsection{CORRESPONDÊNCIA ENTRE O CAMPO CIENTÍFICO E AS ATIVIDADES ECONÔMICAS}

A realização de uma correspondência entre a IPC e a CNAE é algo complexo, visto que ambas classificações possuem finalidades diversas, ou seja, não existe uma conexão direta entre elas. Por um lado, a CNAE destina-se a ordenar de maneira mais detalhada e coerente todos os produtos e serviços produzidos no Brasil (a lógica é agrupar atividades econômicas que utilizam os mesmos insumos e operam de forma similar). Tal classificação é fundamental para diversos aspectos econômicos, como a mensuração da taxa de emprego e do Produto Interno Bruto (PIB), além de facilitar o recolhimento de impostos. Por outro lado, o sistema IPC serve para facilitar o processo de estruturação das áreas científicas atreladas às patentes. Isso auxilia os examinadores de patentes identificarem com precisão as novas características técnicas da invenção, avaliando se os critérios de patenteabilidade estão sendo respeitados (LYBBERT; ZOLAS, 2014).

O quadro 1 apresenta estudos que realizaram as correspondências entre as patentes e as atividades econômicas que foram realizadas até a década de 2010. Essas associações foram realizadas em diferentes países, considerando diversas classificações, tanto de patentes, quanto econômicas.

Quadro 1 - Propostas de correspondência entre tecnologias e atividades econômicas

\begin{tabular}{|c|c|c|c|c|}
\hline \multirow[t]{2}{*}{ Autores } & \multirow[t]{2}{*}{ Ano } & \multirow{2}{*}{$\begin{array}{l}\text { Local ou nome da } \\
\text { correspondência }\end{array}$} & \multicolumn{2}{|c|}{ Classificações utilizadas: } \\
\hline & & & Patente & Econômica \\
\hline Schmmokler & 1966 & EUA & $\begin{array}{l}\text { United States patent } \\
\text { class (USPC) }\end{array}$ & - \\
\hline $\begin{array}{l}\text { Escritório de } \\
\text { patente dos EUA }\end{array}$ & $\ldots$ & EUA & - & - \\
\hline Kronz & 1980 & - & - & - \\
\hline Greif; Potkowik & 1990 & - & - & - \\
\hline Verspargen & 1994 & $\begin{array}{l}\text { Holanda/Merit } \\
\text { Concordance }\end{array}$ & IPC & $\begin{array}{l}\text { International Standard } \\
\text { Industrial } \\
\text { Classification (ISIC) }\end{array}$ \\
\hline
\end{tabular}




\begin{tabular}{|l|l|l|l|l|}
\hline Kortum; Putnam & 1997 & $\begin{array}{l}\text { Canadá/Yale Technology } \\
\text { Concordance (YTC) }\end{array}$ & IPC & $\begin{array}{l}\text { Canadian Standardized } \\
\text { Industrial } \\
\text { Classification }\end{array}$ \\
\hline Johnson & 2002 & OECD Concordance & IPC & ISIC/SIC \\
\hline Schmoch & 2003 & DG Concordance & IPC & ISIC \\
\hline Lybbert; Zolas & 2014 & $\begin{array}{l}\text { Data Mining } \\
\text { Approach/Indexing and } \\
\text { Probabilistic Matching } \\
\text { Approach }\end{array}$ & IPC & Aplicada à diversas \\
\hline
\end{tabular}

Fonte: elaboração própria a partir de Lybbert e Zolas (2014); Schmoch e Francoise et al, 2003.

A concordância de Lybbert e Zolas (2014) superou limitações existentes até então nos trabalhos exposto no quadro 1, visto que eles se restringiam apenas ao contexto, em termos de ano e país, em que foram criados, sem poderem ser aplicados em outros ambientes e épocas. (LYBBERT; ZOLAS, 2014). Portanto, dificilmente podem ser utilizadas como referência para realizar a associação entre invenções tecnologias e atividades econômicas de um grupo definido de patentes, como de um país ou universidade específica.

As concordâncias descritas no quadro 1 , com exceção da última, contém um ou mais problemas (SCHMOCH et al, 2003).

Primeiro, a maioria delas são desprovidas de uma aplicação internacional, por terem sidas construídas com base em uma classificação das atividades econômicas utilizada em um único país. Isso é compreendido ao observar, por exemplo, que Evenson e Putnam (1994) construíram uma oncordância (chamada Yale Technology Concordance) baseada na associação entre a IPC e a Canadian Standard Industrial Classification (CSIC), a qual é específica para este país e, portanto, diferente das de outros países.

Segundo, a classificação de Evenson e Putnam (1994) é estagnada no tempo e válida somente para os anos em que foram baseadas, de 1978 a 1993. Isso por que a dinâmica de invenção intelectual e da evolução da economia faz com que a necessidade tecnológica das diversas indústrias se modifique ao longo do tempo, assim como uma patente altera seu campo de aplicação no longo prazo. Essa mudança conflita com as correspondências (entre patente e atividades econômicas) elaborados manualmente, ou seja, alocando cada patente a um setor produtivo à critério do pesquisador (SCHMOCH et al, 2003). Portanto, uma associação entre as referidas categorias, manualmente construída, é atrelada a um tempo, local e período específico.

Terceiro, Schmoch et al (2003) criticam o fato de que algumas correspondências do Quadro 1 terem sido realizadas em níveis altos de agregação, deixando de lado a possibilidade de alguma compreensão mais detalhada entre a relação das tecnologias e das atividades econômicas.

Quarto, a correspondência de Johnson (2002) partiu da Yale Technology Concordance (construída por Evenson e Putnam (1994)) cuja classificação econômica é a CSIC. Esta, então, foi conectada à ISIC, e assim, foi feito uma liga entre IPC e ISIC. Ou seja, a IPC foi relacionada a CSIC que por sua vez foi conectada a ISIC. Neste processo há uma perda de acuidade e desconfiguração da estrutura inicial (IPC para CSIC).

Nesse sentido, seria desaconselhável tentar construir uma ligação entre a Classificação Industrial Padrão do Canadá com a de outros países e, a partir daí, realizar a correspondência com da IPC das patentes desta segunda nação. Isso por que os resultados desviariam do ideal (LYBBERT; ZOLAS, 2014). Da mesma forma, a utilização de uma organização de patentes específica de uma única nação (como a Classificação de Patentes dos EUA), sem aderência mundial, barra a aplicação dela para outra nação.

Quinto, tanto a classificação de Verspagen et al (1994) - a Merit Concordance - quanto a de Schmoch et al (2003) - a DG Concordance - realizaram a correspondência baseada na International Standard Industrial Classification of All Economic Activities (ISIC) e na IPC, ambas adotadas por muitos países; por isso, teoricamente, poder-se-ia aplicar tal associação como referência para diferentes nações. Todavia, o problema é que o encontro entre as categorias da IPC e da ISIC foram feitas manualmente, uma por uma. Dado esse método, o resultado é destituído de critérios e sujeito a falhas (LYBBERT; ZOLAS, 2014). 
Em resumo, a maioria das correspondências do quadro 1 possuem uma limitada comparação internacional por terem sidas construídas com base em uma classificação das atividades econômicas utilizada em um único país, ao invés de uma padronizada para várias nações. Ademais, elas foram elaboradas por um processo manual, onde cada patente foi atribuída a uma atividade econômica em um determinado país e período. Isso restringe a validade delas a um espaço e a um tempo específico, sem que se possa induzi-las para outros momentos e lugares.

Dada as limitações discorridas anteriormente, restavam apenas duas alternativas para a realização de uma associação com um recorte específico (por exemplo, das patentes de uma universidade e as atividade econômicas de um país). Primeira, adaptar uma correspondência já existente, como a YTC, assumindo sua defasagem temporal e a dificuldade de utilizá-la fora do contexto territorial em que fora criada. Ainda, terse-ia que lidar com a dificuldade de se ajustar duas classificações econômicas diferentes, cada uma delas referente a um país (LYBBERT; ZOLAS, 2014). Segunda, observar patente por patente e manualmente realizar a associatividade entre a classificação tecnológica e a econômica.

Para solucionar os problemas descritos acima, Lybbert e Zolas (2014) criaram um método de correspondência entre a IPC e as estruturas que organizam as atividades econômicas. Os autores propõem uma técnica de associação que supere as restrições, em relação ao tempo e ao local, existentes nas propostas até então elaboradas. Para tanto, eles usam análises de textos, mineração de dados e matching probabilístico.

Ademais, o método de Lybbert e Zolas (2014) embasa-se em programas computacionais, deixando a operação manual em escala mínima. Com isso a correspondência pode ser atualizada em diferentes situações, além de manter-se útil ao longo do tempo. Outrossim, tal metodologia permite analisar a relação entre patentes e diversas atividades econômicas organizadas em diferentes tipos de classificação, tais quais SITC, NACE, ISIC e HS ${ }^{5}$. Por causa disso, ela pode ser aplicada amplamente e de forma direta em diversas situações, locais e períodos. Por todas essas vantagens tal método foi utilizado para analisar a relação entre a IPC-UFRGS e a Divisão-CNAE e está apresentado em detalhes na próxima seção.

\section{METODOLOGIA}

A International Standard Industrial Classification (ISIC) ordena, de forma coerente e consistente, todas as atividades econômicas. Ela segue regras, princípios e concepções acordadas internacionalmente. Sua estrutura é composta por quatro níveis de categorias hierárquicas. O primeiro deles, identificado por uma letra do alfabeto, é a "Seção", a qual organiza a produção em amplos clusters. Logo abaixo, o segundo, posicionasse a "Divisão", com um maior detalhamento. Posteriormente, o terceiro é esmiuçado no "Grupo" que, então, é seguido pelo último - as "Classes", as quais pormenorizam a classificação de todos os produtos e serviços da economia (UNITED NATIONS, 2008).

A seguir, o quadro 2 exemplifica a organização da ISIC. A linha do topo é um código referente a produção de um produto, no caso, bebidas destiladas. As demais linhas detalham os níveis da ISIC para a dita atividade produtiva.

Quadro 2 - exemplo da estrutura da ISIC aplicada a uma atividade econômica

\begin{tabular}{l|l|l}
\hline \multicolumn{2}{c}{ ISIC - exemplo: C1101 } \\
\hline Seção & C & Indústria de transformação \\
\hline Divisão & 11 & Fabricação de bebidas \\
\hline Grupo & 101 & Fabricação de bebidas \\
\hline Classe & 1101 & Fabricação de destilados \\
\hline
\end{tabular}

\footnotetext{
${ }^{5}$ A ALP foi desenvolvida para realizar a correspondência entre a IPC e vários esquemas de se organizar as produções de bens e serviços, tais quais, Standard International Trade Classification (SITC), European Classification of Economic Activities (NACE), International Standard Industrial Classification of all Economic Activities of the United Nations (ISIC) e Harmonized Commodity Description and Coding System of the World Customs Organization (HS). Todavia, este artigo trabalha apenas referenciando a ISIC, dado os objetivos deste artigo.
} 
Fonte: elaboração própria a partir da ISIC (2008).

Vários países aceitam a ISIC como um padrão para categorizar suas atividades de produção. Esse é o caso do Brasil, onde a Classificação das Atividades Econômicas (CNAE) 2.0 é baseada na ISIC 4.0. O primeiro e o segundo nível daquela, respectivamente - Seção e Divisão - são idênticos aos desta. Nos demais dígitos (Grupo e Classe), há peculiaridades inerentes ao sistema produtivo brasileiro, mas mesmo neste caso pouca se difere da ISIC (UNITED NATIONS, 2016).

Já a International Patent Classification (IPC) foi adotada em 1971 pelo acordo de Strasbourg. Ela é uma linguagem de símbolos (numéricos e de letras) que formam um sistema hierárquico de áreas tecnológicas utilizado para a classificação de patentes e modelos de utilidades, como por exemplo "H $03 \mathrm{~F}$ 3/187". Onde o H, até o último conjunto de números (187), corresponde a um dos níveis da IPC: Seção, Classe, Subclasse e Grupo, conforme o quadro 3, apresentado a seguir. Observa-se que para chegar aos circuitos integrados, subgrupo 3/187 - uma tecnologia específica da eletricidade - partiu-se de uma área geral, a eletricidade, seção $\mathrm{H}$.

Quadro 3 - Exemplo: estrutura hierárquica da Internacional Patent Classification
\begin{tabular}{|c|c|}
\hline \multicolumn{2}{|c|}{ H 03 F 3/187 } \\
\hline Seção H & Eletricidade \\
\hline Classe 03 & Circuitos eletrônicos básicos \\
\hline Subclasse F & Amplificadores \\
\hline Subgrupo 3/187 & em circuitos integrados \\
\hline
\end{tabular}

Fonte: elaboração própria a partir da IPC 2016.

\subsection{APLICAÇÃO DO MODELO DE LYBBERT E ZOLAS}

Lybbert e Zolas (2014) construíram um modelo, genericamente denominado "Algorithmic Links with Probabilities", que permite realizar a correspondência entre a IPC e diversas classificações econômicas, como a International Trade Classification ou a ISIC. Para realizar tal conexão entre tecnologia e áreas econômicas, os autores propuseram duas maneiras. A primeira ocorre através de uma abordagem de mineração de dados, onde pode-se ligar a ISIC à IPC, por exemplo. A segunda faz o caminho contrário, parte-se da IPC para associá-la, por exemplo, à ISIC.

No desenvolvimento do referido algoritmo, os autores não limitaram as patentes por um ano ou país e, assim, trabalharam com um volume grande e variado de dados. As patentes pesquisadas advieram da base da World Intellectual Property Organization (WIPO), a PATENTSCOPE6. Já as descrições das atividades econômicas foram retiradas da ISIC.

\subsubsection{Correspondência entre IPC e ISIC: técnica da mineração de dados}

Os autores realizaram uma mineração de $\operatorname{dados}^{7}$ nas patentes disponíveis na base de dados PATENTSCOPE. Primeiramente, eles observaram as descrições de cada atividade econômica e, então,

\footnotetext{
${ }^{6} \mathrm{O}$ banco de dados PATENTSCOPE permite o acesso às patentes do Patent Cooperation Treaty (PCT), bem como àquelas advindas dos escritórios de patentes que participam do PCT. Essa fonte de informações patentárias está disponível em: <http://www.wipo.int/patentscope/en/>.

${ }^{7}$ Mineração de dadosé um método aplicado, sob controle humano, para organizar informações de forma manual e resulta em algoritmos que permitem tanto analisar dados, como a partir deles construir padrões em categorias específicas (KURGAN; PETRMUSILE, 2006). Ele é, assim, um processo de descobrir novos padrões e relações que podem existir a partir de um grande
} 
extraíram termos de busca (palavras-chaves) que a representam. Depois, então, voltaram-se para os títulos e resumos das patentes buscando neles as expressões representativas (palavras-chaves) das atividades econômicas. Por fim, foi feita a frequência ponderada das associações encontradas da seguinte forma:

\section{Frequência ponderada específica (ISIC $\left.i, \mathrm{IPC}_{j}\right)=\left(m_{\mathrm{ij}} / \mathrm{N}_{j}\right) / M i$}

onde $m_{\mathrm{ij}}$ indica o número de patentes que contém a subclasse (da IPC) $j$ dentre todas as que afloraram ao utilizar-se a palavra-chave referente à atividade econômica $i$ da ISIC. Além disso, $\mathbf{N} j$ representa o total do número de patentes da base PATENTSCOPE que contêm a subclasse $j$. Da mesma forma, Mi é o número total de patentes que irrompem com o termo de busca representativo da categoria $i$ da ISIC. Ressalva-se que existe, em muitos casos, múltiplos códigos de IPC associados a uma única patente, assim, cada um deles foi igualmente ponderado, de acordo com a equação (1). Para completar, as frequências foram normatizadas permitindo que suas somas resultem em 1 .

Todavia, o apresentado esquema de pesagem (1) sobrevaloriza as subclasses das IPC com menor frequência em relação àquelas que mais são utilizadas, por isso criou-se, então, uma alternativa, qual seja:

\section{Frequência ponderada híbrida (ISIC $\left.i, \mathrm{IPC}_{j}\right)=\mathrm{s}_{i j} m_{i j} / \sum \mathrm{s}_{i j} m_{i j}(2)$}

onde Sij significa a porção das patentes que engloba a subclasse $j$ cuja atividade econômica ordenada é a $i$. Essa última forma de calcular a frequência ponderada (2) reflete, possivelmente, melhor a natureza das tecnologias ligadas às indústrias, pois ponderar as palavras chaves advindas da classificação econômica pelas subclasses da IPC permite a evidenciação relativamente maior das subclasses que mais aparecem.

\subsubsection{Correspondência entre IPC e ISIC: técnica do índice e da correspondência probabilística}

Cada código da IPC ${ }^{8}$ pode estar associado a diversas atividades econômicas da ISIC, de acordo com diferentes probabilidades. Lybbert e Zolas (2014), para calcular essa probabilidade, ordenaram em clusters os símbolos da IPC inseridos nas patentes, reunindo no mesmo grupo tecnologias similares. Desses grupos foram extraídas palavras-chaves, cada uma delas recebeu um peso, conforme sua importância relativa, determinado pelas quantidades de vezes que um determinado termo aparece em relação ao total. A ponderação dessas expressões chaves foi realizado seguindo a mesma lógica da utilizada na equação (1) e (2), apresentadas anteriormente.

Depois, as expressões que descrevem cada atividade econômica foram cruzadas com as palavraschaves referentes a cada cluster de patentes e, assim, as IPC que representam as tecnologias protegidas foram ligadas às atividades econômicas específicas apropriadas. Cada correspondência recebe um peso de acordo com aquele que foi dado às diferentes palavras-chaves. As atividades econômicas ligadas às expressões que mais peso receberam, dentre o conjunto de termos descritivos das patentes, foram mais valoradas. Por fim, os autores tabularam as indústrias e respectivos pesos, chegando à lista final relacionando a IPC com a ISIC ${ }^{9}$. Um exemplo dessa correspondência probabilística é apresentado na tabela 1 .

Tabela 1 - Exemplo da correspondência probabilística

\begin{tabular}{c|c|c}
\hline Código IPC - nível subclasse & Código ISIC - nível classe & Probabilidade \% \\
\hline A01B & 0150 & 20,3 \\
\hline A01B & 0161 & 9,9 \\
\hline A01B & 0164 & 30,4 \\
\hline
\end{tabular}

volume de dados (ENCYCLOPAEDIA, 2016). Lybbert e Zolas utilizaram a abordagem da mineração de dados (AMD) sobre os títulos e resumos das patentes publicadas no PATSTAT com o intuito de realizar a correspondência entre a IPC e a ISIC.

${ }^{8}$ Neste artigo, foi usado a IPC vigente no primeiro semestre de 2016, a qual continha 8 Seções, 129 Classes e 640 Subclasses, além de milhares de subgrupo (uma divisão específica dentro das subclasses)

${ }^{9}$ A correspondência probabilística completa entre a IPC e a ISIC construída por Lybbert e Zolas (2012) pode ser visualizada no sítio da WIPO (2016) disponível em:<http://www.wipo.int/publications/en/details.jsp?id=3949\&plang=EN>. 


\begin{tabular}{c|c|c}
\hline A01B & 0210 & 3,3 \\
\hline A01B & 2821 & 30,5 \\
\hline A01B & 2822 & 5,4 \\
\hline
\end{tabular}

Fonte: elaboração própria a partir de Lybbert e Zolas (2014).

O código A01B é compartimentado da seguinte forma: "A" é a Seção "Necessidades Humanas"; "A01" é a Classe denominada "Agricultura, silvicultura, pecuária, caça, captura em armadilhas, pesca"; "A01B" é a Subclasse "Trabalho do solo em agricultura ou silvicultura, peças, detalhes ou acessórios de máquinas ou implementos agrícolas, em geral". Essa ordem da IPC é ligada a seis atividades econômica (da ISIC), coluna dois da tabela 1, com um peso diferente para cada uma delas, coluna 3, tabela 1.

\subsection{METODOLOGIA: PATENTES DA UFRGS ASSOCIADA À CNAE}

O principal objetivo do artigo é realizar a correspondência entre os códigos-IPC das patentes da UFRGS com as atividades econômicas da CNAE. Isso contribuirá para o entendimento de quais atividades produtivas são potenciais receptoras das tecnologias protegidas por essa universidade. Para tanto, por um lado, foi realizado um levantamento das patentes e, por outro, definido o nível hierárquico da CNAE cujo cruzamento IPC-CNAE será efetivado.

A listagem das patentes da UFRGS foi gerada no Orbit, sistema de banco de dados comercial que gera informações on-line sobre ativos intelectuais protegidos. Nos campos apropriados de pesquisas dessa ferramenta de busca introduziram-se, no mês de maio de 2016, as palavras-chaves "UFRGS" e "IPC". Não houve limitação de período para se trabalhar com o conjunto integral de patentes depositadas e pulicadas até a citada data, que foi de 344 patentes; cada qual com seus respectivos códigos IPC ${ }^{10}$.

Em seguida, aplicou-se a correspondência probabilística criada por Lybbert e Zolas (2014) para relacionar as IPC extraídas da patente da UFRGS à CNAE, obedecendo-se os pesos da participação de cada código da IPC em diversas divisões da $\mathrm{CNAE}^{11}$. Esta, como já informado, é idêntica à ISIC no primeiro e no segundo nível. Por isso, a correspondência daqueles autores referente à IPC com a ISIC pode ser, ipsis litteris, aplicada àquela entre IPC e a CNAE, nos dois referidos níveis.

\subsubsection{Análise estatística}

A associação entre os símbolos da IPC das patentes da UFRGS e as Divisões da CNAE foi representada em uma matriz, arranjando nas colunas as indústrias e nas linhas os códigos tecnológicos ${ }^{12}$. Depois, ferramentas estatísticas foram utilizadas com o intuito de explorar a referida correspondência e dela retirar novas descobertas acerca do padrão de patenteamento da UFRGS. O software estatístico utilizado foi o SPSS, licenciado por essa instituição.

\footnotetext{
${ }^{10}$ É uma limitação desse trabalho o fato de que o Orbit extrai apenas um único símbolo IPC por patente, apesar do INPI designar, geralmente, mais de um para cada patente. Com isso, a correspondência entre IPC/UFRGS e CNAE, efetivada neste artigo, considera apenas um único código IPC por patente. Porém, na maioria das vezes os diferentes códigos IPC associados a cada patente são idênticos no nível de Seção, Classe e Subclasse, modificando-se com mais frequência nos Subgrupos. Por isso, os resultados da correspondência apresentados aqui não iriam modificar-se significativamente, mesmo que se considerasse todas as IPC utilizadas para classificar cada patente da UFRGS.

${ }^{11}$ Ao aplicar diretamente a correspondência de Lybbert e Zolas (2012), assume-se que as patentes da UFRGS estejam ligadas, com pesos idênticos, as mesmas áreas tecnológicas daquelas patentes do banco de dados utilizado pelos autores. Apesar de que as áreas tecnológicas e as atividades econômicas tendem a se correlacionarem da mesma forma independente da origem das patentes, nem sempre o peso que distribui o código da IPC entre diversas atividades econômicas é o mesmo, mas ele pode mudar de acordo com o grupo patentário selecionado.

12 Ao aplicar a correspondência de Lybbert e Zolas (2014) para o caso específico da UFRGS, assume-se que as patentes da UFRGS estejam ligadas, com pesos idênticos, as mesmas áreas tecnológicas daquelas patentes do banco de dados utilizado pelos autores. Apesar de que as áreas tecnológicas e as atividades econômicas tendem a se correlacionarem da mesma forma, independente do banco de dados, nem sempre o peso que distribui o código da IPC entre diversas atividades econômicas é o mesmo, podendo mudar de acordo com o corte que se dá para selecionar as patentes.
} 
Em seguida, foi aplicada uma análise multivariada, a técnica de Análise de Correspondência (AC), com o intuito de melhorar a visualização e a extração de informações dos dados. Isso auxiliou a verificação das áreas em que a UFRGS mantém produção tecnológica e as possíveis indústrias de aplicação dessas invenções.

O próximo passo foi aplicar o teste Qui Quadrado $\left(x^{2}\right)$ para averiguar se existe (ou não) uma relação estatística significativa entre a classificação de tecnologia e as atividades econômicas. Em outras palavras, foi investigado se as variáveis da tabela de contingência, cuja entrada é composta pelas indústrias (coluna) e códigos IPC/UFRGS (linhas), são estatisticamente correlacionadas.

A AC é útil para interpretar dados de Tabela de Contingência e, a partir delas, gerar hipóteses exploratórias, verificando possíveis associações entre as variáveis categóricas envolvidas e a relação entre linhas e colunas (AGUAYO, 1993). Posteriormente, tais padrões de vinculação podem ser testados com experimentos confirmatórios posteriores, empregando as metodologias usuais da estatística.

Uma tabela de contingência com um grande número de linhas e colunas é complexo de ser representada, visto o enorme volume de pontos esparramados em diferentes espaços geométricos. Caso em que a interpretação dos dados torna-se complicado. Para superar essa dificuldade, técnicas como a AC reduzem a dimensionalidade dessa nuvem de pontos em um subespaço ótimo de dimensão reduzida ${ }^{13}$ (PADRO, 2012).

A Análise de Correspondência (AC) foi usada para transformar a tabela de contingência, que vincula os símbolos da IPC das patentes da UFRGS às Divisões da Indústria, em um mapa facilitador da visualização desses dados categóricos. Isso porque, essa representação gráfica aproxima geometricamente, no espaço, a posição relativa das variáveis categóricas em estudo (PRADO, 2012). Portanto, utilizou-se uma representação em figura que agrupou as categorias que representam a tecnologia com as que exprimem as indústrias.

Posteriormente, um teste Qui Quadrado $\left(x^{2}\right)$ foi aplicado à tabela de contingência que apresenta a relação entre a IPC das patentes da UFRGS as Divisões da CNAE. Isso foi feito porque essa técnica estatística permite analisar se há um padrão de associatividade entre distintas categorias randômicas, ou seja, se elas são independentes ou não (o $x^{2}$ também é conhecido como o teste da independência) (CK-12, 2009). Dessa forma, utilizando-se desse instrumento, foi possível avaliar, estatisticamente, a existência de uma relação entre a IPC e CNAE.

Caso as invenções tecnológicas produzidas pela UFRGS pudessem ser aplicadas com a mesma probabilidade em qualquer indústria da CNAE, então, poder-se-ia esperar que cada Divisão-CNAE fossem igualmente potenciais receptoras de tais inovação. Para confirmar essa expectativa, utiliza-se o teste $x^{2}$, partindo da hipótese que realmente isso acontece. Em outras palavras, está técnica foi usada para responder a seguinte pergunta: as criações patenteadas pela UFRGS são associadas a qualquer tipo de indústria ou apenas a algumas específicas?

O primeiro passo para responder a essa indagação é calcular a matriz do valor esperado correspondente à matriz original que associa os dados das IPC-UFRGS com os da Divisão-CNAE. O valor esperado de cada célula pertinente é calculado como $\frac{L i * C j}{N}$, onde $L i$ representa a soma da linha $i$; $C$ a soma da coluna $j$ e $N$ é o total do número de patentes associadas a cada atividade econômica. $\mathrm{O}$ teste $x^{2}$ é definido como $x^{2}=\sum \sum \frac{\left(O_{i j}-E_{i j}\right)^{2}}{E_{i j}}$, onde $O$ é o valor observado referente a linha $i$ e coluna $j$; e $E$ é o valor esperdo da linha $i$ e coluna $j$ (HOWELL, 2011).

O resultado advindo do cálculo do $x^{2}$ será com o valor da estatística do teste (retirado da tabela de distribuição Qui Quadrada padrão) para estabelecer o valor crítico, considerando 0,05 de nível de significância, com 1 grau de liberdade. Isso possibilitará a rejeição (ou não) da seguinte hipótese básica (Ho): não existe uma associação entre as IPC-UFRGS (que representam as tecnologias dessa instituição) e as diversas Divisões-CNAE. Automaticamente, a hipótese alternativa (H1) é de que há uma associação entre as IPC-UFRGS e as diversas Divisões-CNAE.

As duas ferramentas estatísticas ora brevemente apresentadas será aplicada na correspondência entre a IPC-UFRGS e a Divisão-CNAE. Com esta abordagem é explanatória, busca-se testar ferramentas que possam ser aplicadas na prospecção de mercado para a transferência tecnológica, atividade que tende a crescer nos próximos anos.

\footnotetext{
${ }^{13}$ A abordagem geométrica de como essa redução de espaço é feita pode ser encontrada em trabalhos como: Le Roux e Rouanet (2004), Greenacre e Blasius (2006).
} 


\section{ANÁLISE EDISCUSSÃo DOS RESULTADOS}

A tabela 2 é o resultado da aplicação da correspondência probabilística criada por Lybbert e Zolas (2014). Nesta matriz a primeira coluna registram os códigos das atividades econômicas no nível da DivisãoCNAE e na primeira linha os da IPC das patentes da UFRGS ${ }^{14}$. Cada célula contém o número de patentes cujo campo tecnologia está associado à determinada área produtiva. Esclarece-se que a organização automática das patentes da UFGRS por IPC realizada pelo Orbit extrai apenas um único código IPC para cada patente; quando, normalmente, existem mais de um ${ }^{15}$. Portanto, a tabela 2 considera apenas um símbolo IPC por cada patente da UFRGS.

O primeiro destaque é que $45 \%$ das patentes da UFGRS estão associadas a apenas duas atividades econômicas, "fabricação de produtos químicos" (Divisão 20) e "fabricação de produtos farmo-químicos e farmacêuticos" (Divisão 21). Aquela acopla 83 e esta 72 patentes (números visualizados na última linha da tabela 2). Em terceiro lugar, com 46 patentes (13\% do total), está a "agricultura, pecuária e serviços relacionados" (Divisão 01). Posteriormente, "extração de petróleo e gás natural" (Divisão 6), "fabricação de produtos de metal, exceto máquinas e equipamentos" (Divisão 25) e "fabricação de máquinas e equipamentos" (Divisão 28) contém, cada uma delas, 20 patentes, o que, individualmente, corresponde a $6 \%$ do total.

Evidencia-se que $76 \%$ das patentes da UFRGS estariam conjugadas à apenas seis das 87 Divisões da CNAE $^{16}$. Isso sinaliza que o foco da estratégia de transferência tecnológica da UFRGS seria um rol de atividades econômicas específicas, principalmente aquelas voltadas para bens e produtos ligados à química, agropecuária, minério e máquinas/equipamentos.

O segundo destaque é que $22 \%$ das patentes da UFRGS estão alocadas em apenas duas SubclassesIPC, "Preparações para finalidades médicas, odontológicas ou higiênicas" (A61K) e "atividade terapêutica específica de compostos químicos ou preparações medicinais" (A61P). Aquela acopla 45 e esta 33 patentes (números visualizados na última coluna da tabela 2). Em terceiro lugar, com 23 patentes (7\% do total) está "micro-organismos ou enzimas; suas composições" (C12N). Posteriormente, "investigação ou análise dos materiais pela determinação de suas propriedades químicas ou físicas" $(\mathrm{G} 01 \mathrm{~N})$ registra 21 patentes $(6 \%$ do total), seguida dos "processos químicos ou físicos, p. ex. catálise, química coloidal; aparelhos pertinentes aos mesmos" (B01J) onde alocam-se 19 patentes ( $5 \%$ do total).

Sobressai-se que $40 \%$ das patentes da UFRGS estão classificadas em apenas 5 das 640 Subclasses da IPC. Isso sinaliza que as patentes desta universidade estão focadas em áreas específicas e/ou especializadas. Complementarmente, a ciência química está concatenada com as cinco Subclasses principais, citadas no parágrafo anterior, cuja UFRGS produz mais patentes. Isso vai ao encontro dos campos econômicos cujas correspondências com as patentes-UFRGS seriam as maiores: "fabricação de produtos químicos" e "fabricação de produtos farmo-químicos e farmacêuticos".

\footnotetext{
${ }^{14} \mathrm{O}$ anexo I descreve cada uma das atividades econômicas, no nível de Divisão-CNAE, representadas pelos números da primeira linha da tabela 2; da mesma forma, o anexo II o faz para cada símbolo de patente alocado na primeira coluna.

15 Isso representa uma limitação da pesquisa pelo fato de que uma única patente poderia estar em diferentes linhas da tabela e não em apenas uma, como supostamente se está assumindo. Porém, o programa computacional que realiza automaticamente a classificação das patentes de uma instituição por IPC restringe-se a extrair apenas um único código-IPC por patente. Apesar disso, o exercício continua sendo valido porque, na maioria das vezes, a classe-IPC não muda, diferenciando-se apenas os níveis hierárquicos mais detalhados.

${ }^{16}$ Até 2006 estava vigente a CNAE 1.0, que continha 59 divisões. Mas ela fui substituída pela versão atual, a 2.0, que contém 87 divisões.
} 
Tabela 2 - Correspondência entre a IPC das patentes da UFRGS e a Divisão/CNAE

\begin{tabular}{|c|c|c|c|c|c|c|c|c|c|c|c|c|c|c|c|c|c|c|c|c|c|c|c|c|}
\hline IPC/CNAE & 01 & 02 & 06 & 08 & 10 & 11 & 13 & 18 & 19 & 20 & 21 & 22 & 23 & 24 & 25 & 26 & 27 & 28 & 32 & 35 & 36 & 37 & 43 & \\
\hline $\mathrm{A} 01 \mathrm{H}$ & 5 & 2 & & & & & & & & & & & & & & & & & & & & & & 7 \\
\hline $\mathrm{A} 01 \mathrm{~N}$ & 2 & 0 & & & 0 & & & & & 7 & & & & & & & & & & & & & & 9 \\
\hline \begin{tabular}{|l|}
$\mathrm{A} 01 \mathrm{P}$ \\
\end{tabular} & 2 & 0 & & & 0 & & & & & 3 & & & & & & & & & & & & & & 6 \\
\hline $\mathrm{A} 61 \mathrm{~K}$ & 12 & & & & 2 & & & & & & 31 & & & & & & & & & & & & & 45 \\
\hline \begin{tabular}{|l|}
$\mathrm{A} 61 \mathrm{~L}$ \\
\end{tabular} & 1 & & & & & & 1 & & & 2 & 0 & & & & & & & & 1 & & & & 1 & 7 \\
\hline A61P & 11 & & & & 2 & & & & & & 20 & & & & & & & & & & & & & 33 \\
\hline B01J & & & 8 & & & & & & 1 & 6 & & & 0 & & 3 & & & & & 1 & & & & 19 \\
\hline B29C & & & & & & & 1 & & & 1 & & 2 & & & & & & 2 & & & & & & 6 \\
\hline B82B & & & & & & & & & & 3 & 0 & & & & 3 & 1 & 0 & 1 & & & & & & 8 \\
\hline $\mathrm{B} 82 \mathrm{Y}$ & & & & & & & & & & & 0 & & 1 & & 2 & 1 & & 0 & 3 & & & & & 8 \\
\hline C01B & 0 & & 3 & & & & & & 0 & 2 & & & & & 0 & & & 0 & & 1 & & & & 7 \\
\hline $\mathrm{C02F}$ & & & & & & & & & & & & & & & & & & & & & 1 & 9 & & 10 \\
\hline C07C & 0 & & 3 & 1 & & 1 & & & 3 & 8 & 0 & & & & & & & & & & & & & 16 \\
\hline C07D & 4 & & & & & & & & & 3 & 7 & & & & & & & & & & & & & 14 \\
\hline $\mathrm{C} 07 \mathrm{~F}$ & & & 0 & 1 & & & & & 0 & 4 & 0 & & & & & & & & & & & & & 5 \\
\hline $\mathrm{C} 07 \mathrm{~K}$ & 1 & & & 0 & 0 & & & & & 0 & 6 & & & & & & & 0 & & & & & & \begin{tabular}{|l|}
8 \\
\end{tabular} \\
\hline $\mathrm{C} 08 \mathrm{~F}$ & & & & & & & & & & 11 & & & & & & & & & & & & & & 11 \\
\hline $\mathrm{C} 08 \mathrm{G}$ & & & & & 0 & & & & 2 & 3 & & & & & & & & & & & & & & 6 \\
\hline C08J & & 0 & 0 & & & & & & 1 & 5 & & 1 & & & & & & & & & & & & 8 \\
\hline $\mathrm{C} 08 \mathrm{~K}$ & & 0 & 0 & 1 & 0 & & & & 1 & 8 & & 2 & 0 & & & & & & & & & & & 12 \\
\hline $\mathrm{C} 08 \mathrm{~L}$ & & 0 & 0 & & 0 & & & & 0 & 7 & & 2 & 0 & & & & & & & & & & & 10 \\
\hline C09D & & & & & & & & 0 & & 4 & & & & & 1 & & & & & & & & & 5 \\
\hline \begin{tabular}{|l|}
$\mathrm{C} 12 \mathrm{~N}$ \\
\end{tabular} & 8 & & & & 7 & & & & & 2 & 6 & & & & & & & & & & & & & 23 \\
\hline C12Q & 0 & & & 0 & 0 & & & & & 0 & 0 & & & & & & & 5 & & & & & & \begin{tabular}{|l|}
7 \\
\end{tabular} \\
\hline C23C & & & & & & & & & & 0 & & & 0 & 2 & 4 & 0 & & & & & & & & 7 \\
\hline C25B & & & & & & & & & & 2 & & & & 2 & 1 & & 0 & & & & & & & 6 \\
\hline $\mathrm{C} 25 \mathrm{D}$ & & & & & & & & & & 0 & & & & 2 & 5 & & & & & & & & & 8 \\
\hline G01B & & & & & & & & & & & & & 0 & & & 3 & & 2 & & & & & & 5 \\
\hline G01N & & & 5 & & & & & & & 1 & & & & 1 & & 5 & & 10 & & & & & & 21 \\
\hline H01M & & & & & & & & & & & & & & & 0 & & 6 & & & 0 & & & & 7 \\
\hline soma total & 46 & 4 & 20 & 3 & 13 & 1 & 2 & 0 & 9 & 83 & 72 & 7 & 3 & 7 & 20 & 10 & 7 & 20 & 4 & 2 & 1 & 9 & & 344 \\
\hline
\end{tabular}


A tabela 03 reforça que, em grande medida, as atividades inventivas da UFRGS ocorrem em áreas específicas e especializadas em certos campos científicos. Observa-se, na coluna 1 da Tabela 3, que as patentes se alocam em apenas 15 das 129 Classes da IPC, (11,6\% do total das Classes). Com mais detalhes, existem patentes dessa instituição em apenas 30 das 640 Subclasses (4,6\%. Do total das Subclasses).

\section{Tabela 3 - Dados tecnológicos da UFRGS com base na IPC}

\begin{tabular}{|c|c|}
\hline $\begin{array}{c}\text { Das } 129 \text { classes } \\
\text { da IPC, a } \\
\text { UFRGS está } \\
\text { presente em: }\end{array}$ & $\begin{array}{c}\text { Das } 640 \\
\text { Subclasses da } \\
\text { IPC, a UFRGS } \\
\text { está presente em: }\end{array}$ \\
\hline $15(11,6 \%)$ & $30(4,6 \%)$ \\
\hline
\end{tabular}

Fonte: Elaboração própria a partir das patentes da UFRGS (2016).

Como já dito, ciência química responde por grande parte das patentes da UFRGS, sendo os ramos econômicos "fabricação de produtos químicos" e "fabricação de produtos farmo-químicos e farmacêuticos" os principais absorvedores das patentes desta universidade. Para facilitar a visualização desta conclusão, em outro formato, afigura 1, utilizando a AC, apresenta as mesmas informações da tabela 2.

\section{Figura 1 - Análise de Correspondência: Patentes da UFRGS e as Divisões/CNAE}

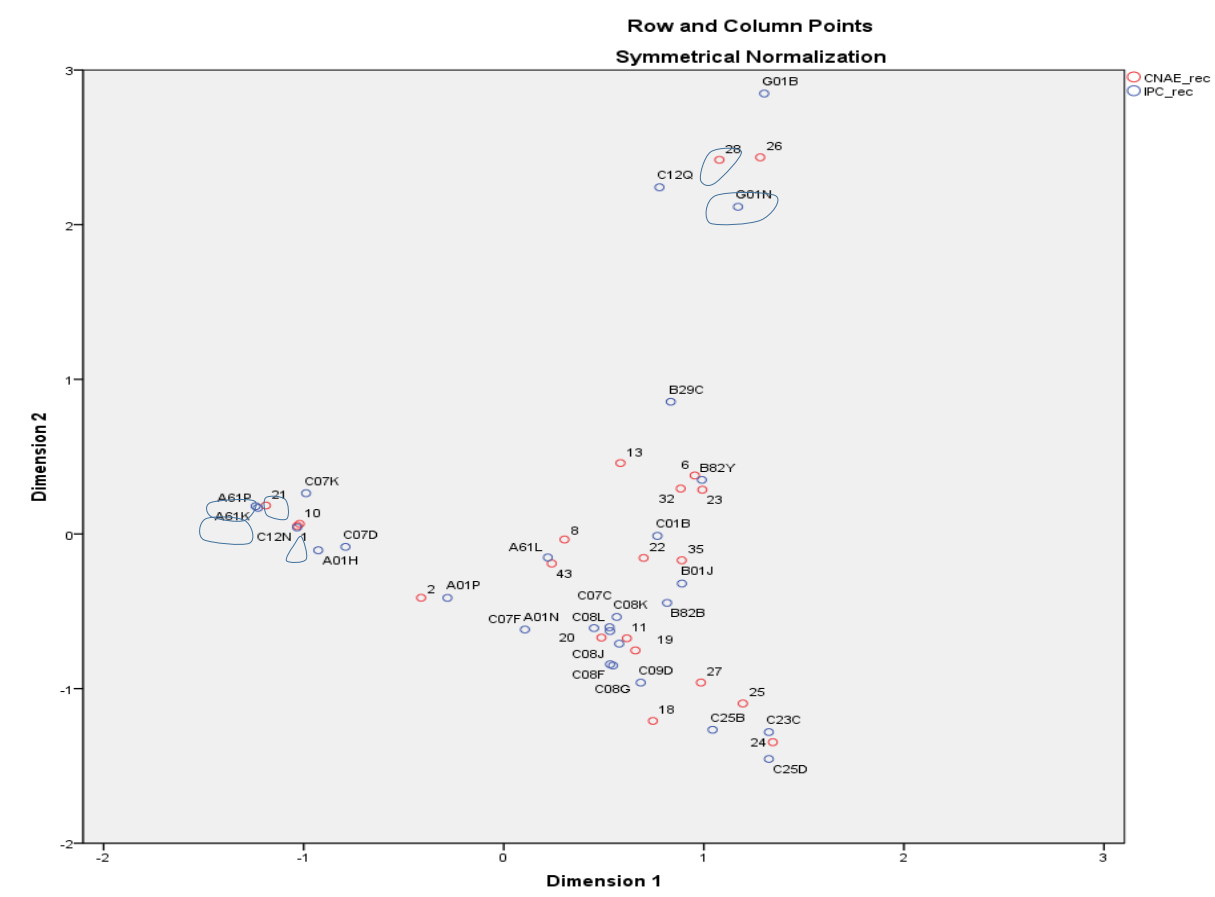

Fonte: elaboração própria com geração eletrônica no programa SPSS.

Na figura 1, fruto da aplicação da AC, as maiores aproximações relativas entre os símbolos IPC-UFRGS e as Divisões-CNAE representam a associação destas duas estruturas. As 5 maiores correspondências em termos de números de patentes são destacadas na figura 1 e explicadas a seguir.

A primeira maior correspondência é entre a "Preparações para finalidades médicas, odontológicas ou higiênicas" (IPC-A61K) e a "Fabricação de produtos 
farmoquímicos e farmacêuticos" (Divisão-CNAE 21), com 31 patentes. Já a segundo maior é entre "atividade terapêutica específica de compostos químicos ou preparações medicinais! (IPC-A61P) e novamente "fabricação de produtos farmoquímicos e farmacêuticos" (Divisão-CNAE 21) tem 20 patentes. Isso evidência que um significativo potencial de criação de produtos químicos voltados à área médica, ou seja, produção de medicamentos.

$\mathrm{Na}$ sequência, a associação entre "Preparações para finalidades médicas, odontológicas ou higiênicas" (IPC-A61K) liga-se à classe econômica "agricultura, pecuária e serviços relacionados" (Divisão-CNAE 01), com 12 patentes. Sucessivamente, "atividade terapêutica específica de compostos químicos ou preparações medicinais" (IPC-A61P) está ligada à "agricultura, pecuária e serviços relacionados" (Divisão-CNAE 01), com 11 patentes. Isso sugere que a terceira e quarta maiores ligações tem um viés para produtos de defensivos agrícolas e vacinas veterinárias.

O quinto vínculo refere-se àquele entre "investigação ou análise dos materiais pela determinação de suas propriedades químicas ou físicas" (IPC-G01N) e a atividade "fabricação de máquinas e equipamentos" (Divisão-CNAE 28). Isso pode ser uma revelação de um potencial para criação de máquinas, equipamentos ou instrumentos úteis para investigações das propriedades de diferentes materiais. Ainda nesse caso, a química está presente e se relacionando à engenharia de materiais.

Uma vez que a análise exploratória realizada acima propôs relações focadas em áreas específicas entre a IPC-UFRG e a Divisão-CNAE, aplica-se, agora, um teste Qui Quadrado $\left(x^{2}\right)$ para verificar, estatisticamente, se é possível confirmar isso. Tal ferramenta estatística permite responder à seguinte questão: as criações patenteadas pela UFRGS são associadas a qualquer tipo de indústria ou apenas a algumas específicas? Para tanto, duas hipóteses são levantadas: Ho - não existe uma associação entre as IPC das patentes da UFRGS e as diversas Divisões-CNAE; ou alternativamente, $\mathrm{H} 1$ - existe uma associação entre as IPC das patentes da UFRGS e as diversas Divisões-CNAE.

O resultado do teste estatístico configurou-se da seguinte maneira: $x^{2}(638, \mathrm{~N}=$ $331)=2195, \rho=0,00$. Portanto, a probabilidade de que $x^{2}$ seja maior do que $638 \mathrm{com}$ 331 graus de liberdade é praticamente zero. Assim, pode-se rejeitar a hipótese nula de que não existe uma associação entre as IPC das patentes da UFRGS e diversas DivisõesCNAE. Em outras palavras, existe uma relação significativa entre as patentes da UFRGS e as atividades econômicas. Conclui-se que as patentes da UFRGS têm maior probabilidade de estarem mais ligadas com algumas indústrias, em especial, do que com outras.

\section{CONSIDERAÇÕES FINAIS}

O trabalho ora apresentado auxilia na reflexão acerca de um tema fundamental para o futuro do desenvolvimento econômico do país, que é a aplicação industrial das criações das universidades. Uma vez que o conhecimento científico será cada vez mais importante para a produção das atividades econômicas, as ações de transferência tecnológica das universidades para as empresas intensificar-se-ão. Por isso, cada vez mais os gestores se preocupam com as possíveis aplicações econômicas das invenções que resultam das pesquisas. Neste caso, cabe aperfeiçoar os mecanismos de interação entre estas organizações. Um caminho que já vem sendo traçado no Brasil é o encorajamento da comercialização das invenções das ICT, inclusive permitindo retornos financeiros advindos da pesquisa acadêmica. Em que pese a oposição a tal modelo, é fato que ele já avançou nos países desenvolvidos com resultados positivo para a inovação. Inclusive é 
recorrente a presença de alguma universidade com intensa interação com empresas de base tecnológica em territórios que contém clusters de inovação.

Mesmo que a negociação dos ativos intelectuais das universidades torna-se cada vez mais recorrente, a relação universidade-empresa carece de estudos que possam esclarecer como tal interação pode ser estabelecida de maneira a beneficiar a sociedade. No Brasil, os NTI possuem pouca experiência no processo de transferência de tecnologia e clamam por mecanismos que possam impulsionar este processo. Daí a relevância deste artigo, contextualizado no debate sobre ferramentas que possibilitem a conexão entre as criações advindas das pesquisas universitárias e o sistema produtivo. $\mathrm{O}$ resgata a discussão internacional sobre correspondência da IPC com atividades econômicas, apresenta o estado da arte, e faz uma primeira experimentação com as patentes da UFRGS. Como um primeiro passo, muito trabalho ainda pode ser feito, como construir uma correspondência genuinamente brasileira, com base nos dados de patentes do Brasil.

Em todo o caso, a transcrição da linguagem tecnológica para uma econômica contribui para visualizar potenciais clientes absorvedores das inovações das instituições de pesquisas. Neste sentido, esse trabalho realizou a correspondência entre as patentes da UFRGS e a CNAE. A metodologia utilizada para isso está em um estágio inicial de discussão na WIPO e é relevante para aprimorar a transferência tecnológica, ao construir um mapa contendo a associatividade entre tecnologias e indústrias específicas. Apesar desta discussão no âmbito internacional, este trabalho é o primeiro artigo atualizado que busca utilizar a referida correspondência nas patentes brasileiras.

O método de correspondência entre a IPC e as atividades econômicas desenvolvido por Lybbert e Zolas (2014) foi o primeiro a automatizar tal processo, antes feito manualmente e segundo o julgamento do pesquisador. O presente artigo realizou uma contribuição ao realizar uma aplicação a um caso brasileiro do referido método. Avançou ainda mais ao testar estatisticamente a validade da correspondência dos autores através dum teste Qui Quadrado $\left(x^{2}\right)$. Este concluiu que existe uma relação significativa entre as patentes da UFRGS e as atividades econômicas (indústria) específicas. Além disso, na análise de correspondência visualizou-se de maneira mais clara a relação entre patentes e atividade econômica. Isso abre a possibilidade de se realizar análises semelhantes para outras ICT.

A correspondência entre as patentes da UFRGS e as atividades econômicas pode auxiliar na tomada de decisão com relação ao estudo de inteligência competitiva com vistas à transferência tecnológica da UFRGS para as empresas. Ou seja, este artigo explorou uma estratégia que pode tornar a transferência tecnológica mais eficiente. A partir disso, sugere-se ao NIT da UFRGS desenvolver estudos de mercado e ações de interação com empresas incluídas nas indústrias mapeadas por este artigo.

Em resumo, no caso da UFRGS, as tecnologias com aplicação nas áreas médicas, odontológicas ou higiênicas e terapêuticas estão voltadas primeiramente para as indústrias química e de farmácia e, em segundo lugar, às atividades agropecuárias. Neste último caso, destaca-se o potencial para o desenvolvimento de defensivos agrícolas e vacinas animais. Complementarmente, na quinta maior correspondência aparece a indústria de máquinas e equipamentos voltada à pesquisa de materiais.

Para fins de pesquisas futuras, fica o desafio de realizar uma correspondência entre a CNAE e todas as patentes do Brasil para construir uma associação entre estas classificações genuinamente brasileira. 


\section{REFERÊNCIAS}

AGUAYO, M. T.V. Análise de Correspondência e Modelos Log-Lineares: um Enfoque Integrado para a Análise Exploratória de Dados Categóricos. Tese (Doutorado em Economia) - Instituto de Matemática Estatística e Ciência da Computação, Universidade Estadual de Campinas, 1993.

BOYD, E.; CHO, M.; BERO, L. Financial conflict of interest policies in clinical research: issues for clinical investigators. Academic Medicine 78, p. 769-774, 2003.

BRASIL. Lei $\mathrm{n}^{\circ}$ 10.973/2004, de 2 dezembro de 2004. Dispõe sobre incentivos à inovação e à pesquisa científica e tecnológica no ambiente produtivo e dá outras providências. Diário Oficial [da] República Federativa do Brasil, Brasília, DF, p. 2,3 dez. 2004. Disponível em: <http://www.planalto.gov.br/ccivil_03/_ato20042006/2004/lei/110.973.htm>. Acesso em: 19 mai. 2015.

BRASIL. Lei n ${ }^{\circ}$ 13.243/2016, de 11 de janeiro de 2016. Dispõe sobre estímulos ao desenvolvimento científico, à pesquisa, à capacitação científica e tecnológica e à inovação .... Diário Oficial [da] República Federativa do Brasil, Brasília, DF, p. 1, 12 jan, 2012.

BUENSTORF, G.; GEISSLER, M. Not invented here: technology licensing, knowledge transfer and innovation based on public research. Journal of Evolutionary

Economics, [S.L.], v. 22, n. 3, p. 481-511, 2012.

CASTRO, B. S., \&SOUZA, G. C. (2012). O papel dos Núcleos de InovaçãoTecnológica (NITs) nas universidades brasileiras. Liinc em Revista, 8(1), 125 140.

http://revista.ibict.br/liinc/index.php/liinc/article/viewFile/465/360.

CK-12. Probability and statistics (Advanced). Palo Alto, CA-US: Flexbook, 2009.

ENCYCLOPAEDIA BRITANNICA. School and library subscribers. 2016.

Disponível em: <https://global.britannica.com/technology/data-mining > . Acessado em: 16 set. 2016.

EVENSON, R.; PUTNAN, J.“Inter-Sectoral Technology Flows: Estimates from a Patent Concordance with an Application to Italy," Yale University Mimeo, 1994.

EVERITT, B. S. The analysis of contingency tables. Londres: Champman \& Hall, 1992.

GREENACRE, M. J.; BLASIUS, J..Multiple correspondence analysis and related methods. Boca-Raton: Chapman-Hall, 2006.

HOWELL, D. C. Chi-Square test: analysis of contingency tables. In LOVRIC, M. International Encyclopedia of Statistical Science. Berlin: Springer-Verlag, 2011.

JOHNSON, D.K.N. The OECD technology concordance (OTC): Patents by industry of manufacture and sector of use. SIT Working papers 2002/5. Paris: OCDE, 2002 
LE ROUX, B.; ROUANET, H. Geometric data analysis. From correspondence analysis to structured data analysis. Dordrecht, the Netherlands: Kluwer-Springer, 2004.

LYBBERT, T. J.; ZOLAS, N. J. Getting patents and economic data to speak to each other: An 'algorithmic links with probabilities' approach for joint analyses of patenting and economic activity. Amsterdam, Research Policy, v. 43, n. 3, p. 530-542, 2014.

MUELLER, S. P. M.; PERUCCHI, V. Universidades e a produção de patentes: tópicos de interesse para o estudioso da informação tecnológica. Perspectivas em Ciência da Informação, Belo Horizonte, v.19, n.2, p.15-36, 2014.n.1, p. 125-140, 2012.

OECD. Patents as Statistical Indicators of Science and Technology. Paris: OECD Patent Statistics Manual, 2009. Disponível em: <http://dx.doi.org/10.1787/9789264056442-3-en>. Acesso: 15/09/2016.

OLIVEIRA, L. G.; NUNES, J. S. O uso do sistema de patentes pela universidade brasileira. A ciência da informação criadora do conhecimento. Coimbra, v. 2, n. [S.I] 2009. Disponível em: <http://www.inpi.gov.br/publicacoes >. Acesso em 23/09/2016.

PEREIRA, F. C.; MELLO, J. M. C. Depósito de patentes de universidades brasileiras na base do INPI. XXXV Encontro Nacional de Engenharia de Produção. Fortaleza, 1316 out., 2015.

PÓVOA, L. M. C. Patentes de universidades e institutos públicos de pesquisa e a transferência de tecnologia para empresas no Brasil, 2008, 153f. (Tese de Doutorado em Economia) - Centro de Desenvolvimento e Planejamento Regional, Faculdade de Ciências Econômicas, Universidade Federal de Minas Gerais, Belo Horizonte, 2008.

POWELL, W. W; SNELlMAN K. The Knowledge Economy. Annual Reviews. V. 30. P 199-220. 2004.

PRADO, M. V. B. Métodos de análise de correspondência múltipla: estudo de caso aplicado à avaliação da qualidade do café. Dissertação (Mestrado em Estatística) Departamento de Ciências Exatas, Universidade Federal de Lavras, 2012.

SCHMOCH, U.; LAVILLE, et al.Linking Technology Areas to Industrial Sectors. Karlsrushe: DG Research, nov. 2003. (Final Reports to the European Commission). Disponível em: $\langle$ https://cordis.europa.eu/pub/indicators/docs/ind_report_isi_ost_spru.pdf $>$. Acesso em: 25-09-2016.

SHARPE, D. Your Chi-Square test is statistically significant: now what? [S.L.]: Practical Assessment, Research \& Evaluation, v. 20, n. 8. Disponível em: $<$ http://pareonline.net/getvn.asp? $\mathrm{v}=20 \& \mathrm{n}=8$ > . Acesso em: 24-09-2016.

THURSBY, M.; THURSBY, J.; GUPTA-MUKHERJEE, S. Are there real effects of licensing on academic research? A life cycle view. [S.L.], Journal of Economic Behavior \& Organization, vol 64, n. 4, 2007. 
UNITED NATIONS. International Standard Industrial Classification. Statistical Papers. New York: Series M, N 4, rev. 4, 2008.

UNITED NATIONS. United Nations Statistics Division. 2016. Disponível em $<$ http://unstats.un.org/unsd/cr/ctryreg/ctrydetail.asp?id=1036>. Acessado em: 19 set. 2016.

VERSPAGEN, B.; MORGASTEL, T.; SLABBERS, M. MERIT concordance table: IPC-ISIC (rev. 2), Maastricht: MERIT Research Memorandum 2/94-004, 1994.

WIPO. World Intellectual Property Organization. 2016. Disponível em $\langle$ http://www.wipo.int/publications/en/details.jsp?id=3949\&plang=EN >. Acessado em: 19 set. 2016. 


\section{ANEXO I - Divisão da CNAE associadas com as IPC-UFRGS}

\begin{tabular}{|l|l|}
\hline 01 & agricultura, pecuária e serviços relacionados \\
\hline 02 & produção florestal \\
\hline 06 & extração de petróleo e gás natural \\
\hline 08 & extração de minerais não-metálicos \\
\hline 10 & fabricação de produtos alimentícios \\
\hline 11 & fabricação de bebidas \\
\hline 13 & fabricação de produtos têxteis \\
\hline 18 & impressão e reprodução de gravações \\
\hline 20 & fabricação de coque, de produtos derivados do petróleo e de biocombustíveis \\
\hline 21 & fabricaçãão de produtos farmoquímicos e farmacêuticos \\
\hline 22 & fabricação de produtos de borracha e de material plástico \\
\hline 23 & fabricação de produtos de minerais não-metálicos \\
\hline 24 & Metalurgia \\
\hline 25 & fabricação de produtos de metal, exceto máquinas e equipamentos \\
\hline 26 & fabricação de equipamentos de informática, produtos eletrônicos e ópticos \\
\hline 27 & fabricação de máquinas, aparelhos e materiais elétricos \\
\hline 28 & fabricação de máquinas e equipamentos \\
\hline 32 & fabricação de produtos diversos \\
\hline 35 & eletricidade, gás e outras utilidades \\
\hline 36 & captação, tratamento e distribuição de água \\
\hline 37 & esgoto e atividades relacionadas \\
\hline 43 & serviços especializados para construção \\
\hline
\end{tabular}

\section{ANEXO II - IPC das patentes da UFRGS associadas com as Divisões CNAE}

\begin{tabular}{|l|l|}
\hline A01H & $\begin{array}{l}\text { novas plantas ou processos para obtenção das mesmas; reprodução de plantas por } \\
\text { meio de técnicas de cultura de tecidos }\end{array}$ \\
\hline A01N & $\begin{array}{l}\text { conservação de corpos de seres humanos ou animais ou plantas ou partes dos } \\
\text { mesmos }\end{array}$ \\
\hline A01P & $\begin{array}{l}\text { atividade de compostos químicos ou preparações biocidas, repelentes ou atrativos de } \\
\text { pestes ou reguladores do crescimento de plantas }\end{array}$ \\
\hline A61K & Preparações para finalidades médicas, odontológicas ou higiênicas \\
\hline A61L & $\begin{array}{l}\text { métodos ou aparelhos para esterilizar materiais ou objetos em geral; desinfecção, } \\
\text { esterilização ou desodorização do ar; aspectos químicos de ataduras, curativos, } \\
\text { almofadas absorventes ou artigos cirúrgicos; materiais para ataduras, curativos, } \\
\text { almofadas absorventes ou artigos cirúrgicos }\end{array}$ \\
\hline A61P & atividade terapêutica específica de compostos químicos ou preparações medicinais \\
\hline B01J & $\begin{array}{l}\text { processos químicos ou físicos, p. ex. catálise, química } \\
\text { coloidal; aparelhos pertinentes aos mesmos }\end{array}$ \\
\hline B29C & $\begin{array}{l}\text { modelagem ou união de matérias plásticas;modelagem de substâncias em estado } \\
\text { plástico, em geral; pós-tratamento de produtos modelados, p. ex. reparo }\end{array}$ \\
\hline
\end{tabular}




\begin{tabular}{|c|c|}
\hline B82B & $\begin{array}{l}\text { nano estruturas formadas por manipulação individual de átomos, moléculas, ou } \\
\text { grupos limitados de átomos ou moléculas como unidades discretas; fabricação ou } \\
\text { seu tratamento }\end{array}$ \\
\hline B82Y & $\begin{array}{l}\text { usos específicos ou aplicações de nano estruturas; medidas ou análises de nano } \\
\text { estruturas; fabricação ou tratamento de nano estruturas }\end{array}$ \\
\hline C01B & elementos não-metálicos; seus compostos \\
\hline $\mathrm{C} 02 \mathrm{~F}$ & tratamento de água, de águas residuais, de esgotos ou de lamas e lodos \\
\hline $\mathrm{C} 07 \mathrm{C}$ & compostos acíclicos ou carbocíclicos \\
\hline C07D & compostos heterocíclicos \\
\hline $\mathrm{C} 07 \mathrm{~F}$ & $\begin{array}{l}\text { compostos acíclicos, carbocíclicos ou heterocíclicos contendo outros elementos que } \\
\text { não o carbono, o hidrogênio, o halogênio, o nitrogênio, o enxofre, o selênio ou o } \\
\text { telúrio }\end{array}$ \\
\hline $\mathrm{C} 07 \mathrm{~K}$ & $\begin{array}{l}\text { compostos acíclicos, carbocíclicos ou heterocíclicos contendo outros elementos que } \\
\text { não o carbono, o hidrogênio, o halogênio, o nitrogênio, o enxofre, o selênio ou o } \\
\text { telúrio }\end{array}$ \\
\hline $\mathrm{C} 08 \mathrm{~F}$ & $\begin{array}{l}\text { compostos macromoleculares obtidos por reações compreendendo apenas ligações } \\
\text { insaturadas carbono-carbono }\end{array}$ \\
\hline $\mathrm{C} 08 \mathrm{G}$ & $\begin{array}{l}\text { compostos macromoleculares obtidos por reações outras que não envolvendo } \\
\text { ligações insaturadas carbono-carbono }\end{array}$ \\
\hline $\mathrm{C} 08 \mathrm{~J}$ & $\begin{array}{l}\text { elaboração; processos gerais para formar misturas; pós-tratamento não abrangido } \\
\text { pelas subclasses }\end{array}$ \\
\hline $\mathrm{C} 08 \mathrm{~K}$ & $\begin{array}{l}\text { uso de substâncias inorgânicas ou orgânicas não-macromoleculares como } \\
\text { ingredientes de composições }\end{array}$ \\
\hline $\mathrm{C} 08 \mathrm{~L}$ & composições de compostos macromoleculares \\
\hline C09D & $\begin{array}{l}\text { composições de revestimento, p. ex. tintas, vernizes ou lacas; pastas de } \\
\text { enchimento;removedores químicos de tintas para pintar ou imprimir; tintas para } \\
\text { imprimir; líquidos corretivos; corantes para madeira; pastas ou sólidos para colorir ou } \\
\text { imprimir; uso de materiais para esse fim }\end{array}$ \\
\hline $\mathrm{C} 12 \mathrm{~N}$ & micro-organismos ou enzimas; suas composições \\
\hline $\mathrm{C} 12 \mathrm{Q}$ & $\begin{array}{l}\text { processos de medição ou ensaio envolvendo enzimas ou micro- } \\
\text { organismos (imunoensaiosg01n 33/53);suas composições ou seus papéis de } \\
\text { teste;processos de preparação dessas composições;controle responsivo a condições } \\
\text { do meio nos processos microbiológicos ou enzimáticos }\end{array}$ \\
\hline $\mathrm{C} 23 \mathrm{C}$ & $\begin{array}{l}\text { revestimento de materiais metálicos;revestimento de materiais com materiais } \\
\text { metálicos; tratamento da superfície de materiais metálicos por difusão, por } \\
\text { conversão química ou substituição; revestimento por evaporação a vácuo, por } \\
\text { pulverização catódica, por implantação de ions ou por deposição química em fase de } \\
\text { vapor, em geral }\end{array}$ \\
\hline $\mathrm{C} 25 \mathrm{~B}$ & $\begin{array}{l}\text { processos eletrolíticos ou eletroforéticos para a produção de compostos ou de não } \\
\text { metais;aparelhos para esse fim }\end{array}$ \\
\hline $\mathrm{C} 25 \mathrm{D}$ & processos para produção eletrolítica ou eletroforética de revestimentos; eletrotipia \\
\hline G01B & $\begin{array}{l}\text { medição de comprimentos, espessuras ou outras dimensões lineares } \\
\text { semelhantes; medição de ângulos;medição de áreas; medição de irregularidades de } \\
\text { superfícies ou contornos }\end{array}$ \\
\hline G01N & $\begin{array}{l}\text { investigação ou análise dos materiais pela determinação de suas propriedades } \\
\text { químicas ou físicas }\end{array}$ \\
\hline & $\begin{array}{l}\text { processos ou meios, p. ex. baterias, para a conversão direta da energia química em } \\
\text { energia elétrica }\end{array}$ \\
\hline
\end{tabular}

